\title{
Kıyı Ege'nin (Gökova ve Edremit Körfezleri Arası) Vejetasyon Ekolojisi ve Biyolojik Çeşitliliğinin Ekolojik Yönetimi
}

\author{
Yurdanur AKYOL ${ }^{1 *}$, Yusuf GEMIC ${ }^{2}$ \\ ${ }^{1}$ Manisa Hasan Türek Anadolu Lisesi, Yunusemre, Manisa/Türkiye \\ ${ }^{2}$ Ege Üniversitesi, Fen Fakültesi, Biyoloji Bölümü, Bornova, İzmir/Türkiye \\ * Sorumlu Yazar: yurdanur45@gmail.com
}

Geliş Tarihi: 16.08.2016

Kabul Tarihi:13.02.2017

Özet: Bu çalışma Batı Anadolu'da bulunan Balıkesir, İzmir, Aydın ve Muğla il sınırları içerisinde yer alan Kıyı Ege'de gerçekleştirilmiştir. Çalışmanın amacı, bölgenin vejetasyon ekolojisi, sintaksonomik durumu ve biyolojik çeşitliliğinin belirlenmesi ve buna bağlı olarak mevcut ve potansiyel tehlikeler ile alanın sürdürülebilirliğini sağlamak üzere ekolojik yönetim bazında alınması gereken önlemlerin ortaya konulması amacıyla gerçekleştirilmiştir. Çalışma alanının vejetasyonu 2005-2008 yılları arasında yapılan arazi çalışmalarında Braun-Blanquet yöntemine göre araştırılmıştır. Ege Kıyılarında çeşitli kıyı ekosistemlerinin varlığı biyoçeşitliliğin zenginliğini göstermektedir. Bu çalışmada saptanan oniki bitki birliğinin altısı yeni tanımlanmıştır.

Anahtar Kelimeler: Ekolojik yönetim, Kıyı Ege, Vejetasyon ekolojisi

\section{Vegetation Ecology and Ecological Management of Biodiversity of Coastal Aegean (Between Edremit and Gökova Gulfs) in Turkey}

\begin{abstract}
This study was carried out in the area coastal Aegean within the borders of the Balıkesir, İzmir, Aydın and Muğla province at the Western Anatolia. This study aimed to define the vegetation ecology, syntaxonomic status and biodiversity of the region, and to ensure the sustainability of the area against available and potential hazards to determine the measures to be taken on the basis of ecological management. The vegetation of the study area was researched according to the Braun-Blanquet method in field studies conducted between 2005-2008. The presence of a variety coastal ecosystems is enriching the biodiversity in the Aegean coasts. At the end of this study, twelve plant associations have been detected and six of them newly described.
\end{abstract}

Keywords: Coastal Aegean, Ecological management, Vegetation ecology

\section{Giriş}

Ege Bölgesi, Baba Burnu'ndan Dalaman Çayı ağzına kadar devam eden 2593 km uzunluğunda bir kıyı kuşağına sahiptir. Kıyı Ege'de dağlar denize dik uzanmaktadır. Bu durum Gediz, Büyük Menderes ve Bakırçay deltaları gibi alüvyon açıdan zengin havzalar ve üretken deltalar oluşturmuştur. Dağların kıyıya göre pozisyonu, bu kesimde birçok koydan oluşan girintili çıkıntılı kıyılara neden olmuştur. Bu kıyılar ulusal ve uluslararası ölçekte öneme sahip çok sayıda duyarlı ekosistemler bulundurmaktadır. Bunlardan Gediz Deltası 1998 tarihinde Ramsar Alanı olarak ilan edilmiştir. Eken ve ark. (2006)'ya göre diğer önemli doğa alanları içerisinde Küçük Menderes Deltası, Akbük Kıyıları, Ayvalık adaları, Bakırçay Deltası, Büyük Menderes Deltas1, Bodrum Yarımadas1, Çeşme Batı Burnu, Dilek Yarımadası, Doğanbey Kıyıları, Foça Yarımadası, Gökova Kuzey Kıyıları sayılabilir. Kıyı ekotonlarının yüksek biyoçeşitliliğe sahip olması çok sayıda araştırmacının dikkatini çekmiş ve bu biyoçeşitliliği araştırmak üzere çok sayıda çalışmalar yapmışlardır (Bekat, 1980; Uslu, 1985; Bekat ve Seçmen, 1988; Görk ve ark., 2001; Oluk ve ark., 2001; Pirhan ve Gemici, 2015). 
Vejetasyon ekolojisi ve sintaksonomik çalışmalar kıyı alanlarında mevcut durumun tanımlanmasi ve ekosistemde bulunan nadir ya da anahtar türlerin tespiti ile biyolojik çeşitliliğin korunmasına yönelik yönetim planlarının belirlenmesinde önemli rol oynamaktadır. Bu çalışmada amacımız alanın bitki biyoçeşitliliğinin belirlenerek bu biyoçeşitliliğin korunmasına yönelik yönetim planlarının oluşturulmasına katkı sağlamaktır.

\section{Materyal ve Metot}

Çalışma alanı kuzeyde Edremit Körfezi ve güneyde Gökova Körfezi ile sınırlı olan Kıyı Ege Bölgesi'ni kapsamaktadır (Şekil 1). Yapılan çalışmalar arazi çalışmaları ve yönetim planlarının oluşturulması olmak üzere iki aşamada gerçekleştirilmiştir. Arazi çalışmaları için 2005 ve 2008 yılları arasında çalışma alanına periyodik aralıklarla gidilerek toplanan bitki örnekleri preslenerek herbaryum materyali haline getirilmiş ve "Flora of Turkey The Aegean Islans" adlı eserden bitki örnekleri teşhis edilmiştir (Davis, 1965-1985; Davis ve ark., 1988; Güner ve ark., 2000). Çalışma bölgemizin vejetasyonu ülkemizde de yaygın olarak kullanilan Braun-Blanquet (1932)'in yöntemine göre araştırılmıştır. $\mathrm{Bu}$ amaçla arazi çalışmalarında homojen olduğu düşünülen yerlerde deneme alanlar alınmıştır. Örnek alanların büyüklüğü "en küçük alan" yöntemi esas alınarak belirlenerek, tuzcul ve kumul alanlarda $25 \mathrm{~m}^{2}$ diğer alanlarda $100 \mathrm{~m}^{2}$ olacak şekilde örnek alandan örnekleme alınmıştır. Belirlenen birliklerin sintaksonomik durumlarının tespitinde ilgili referanslar kullanılmıştır (Quezel ve ark., 1992). Yeni olarak tanımlanan sintaksonların adlandırılmasında "Uluslararası Bitki Sosyolojisi Adlandırma Kodu" kurallarına uyulmuştur (Weber ve ark., 2001).

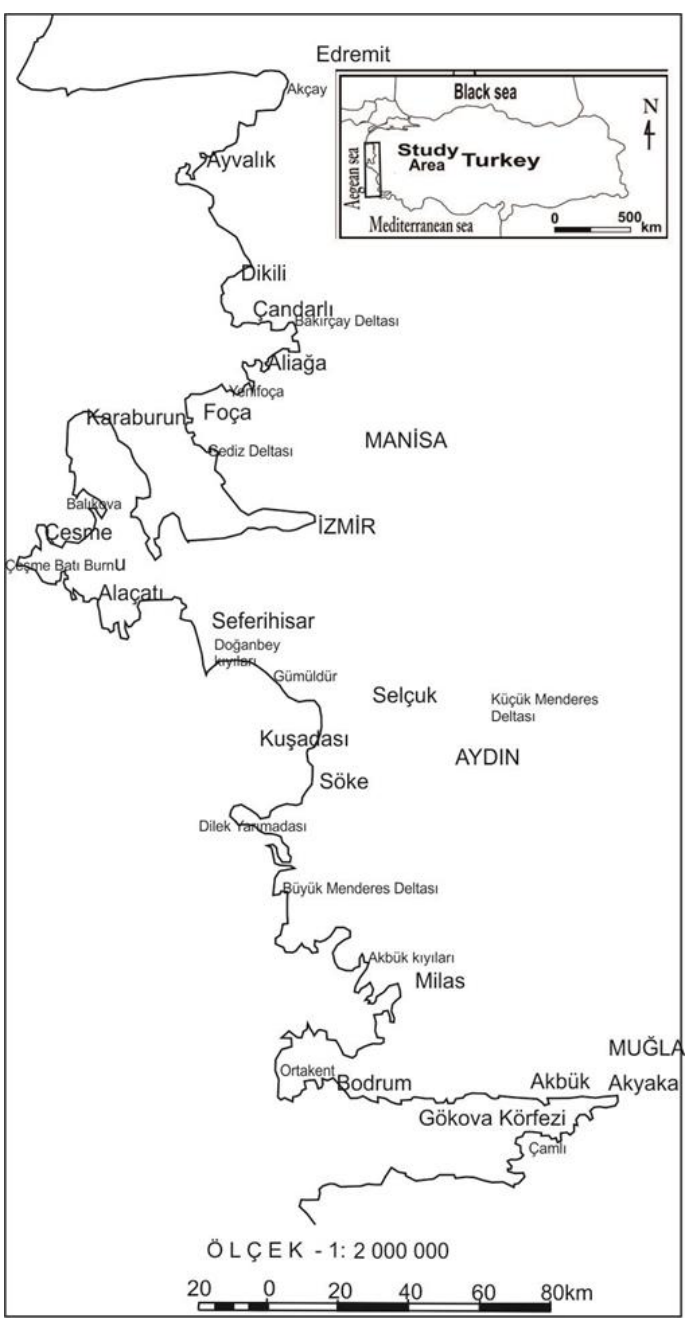

Şekil 1. Çalışma alanı ve lokaliteler

\section{Bulgular ve Tartışma}

Vejetasyon çalışmaları sonucunda alanda toplam 5 vejetasyon tipi ve 6'sı bu çalışmada yeni tanımlanan 12 bitki birliği belirlenmiştir.

Birlikler ve ait oldukları üst birimler şu şekildedir:

Sınıf: AMMOPHILETEA Br.-B1. \& Tüxen ex Westhoff, Dijk \& Passchier, 1946

Ordo: AMMOPHILETALIA Br.-Bl., 1933

Alyans: AMMOPHILLION AUSTRALIS

Br-Bl. 1921, corr. Rivas-Martinez \&. all., 1990

Birlik: Medicio marinae - Cakilietum maritimae ass. nova

Birlik: Euphorbio paraliae-Ammophiletum arundinaceae Uslu 1985 
Birlik: Anthemo tomentosae-Centauretum spinosae ass. nova

Sinıf: SALICORNIETEA FRUTICOSAE

Br.-B1. \& Tüxen ex A. \& O. Bolos 1950

(syn: Arthrocnemetea fruticosi Tx. \& Oberd. 1958)

Ordo: SALICORNIETALIA FRUTICOSAE Br.-B1. 1933

Birlik: Salicornio europeae - Juncetum acutus ass. nova

Birlik: Parapholio incurvae-Aeluropetum littoralis ass. nova

Birlik: Salicornio europeae-Halimionetum portulacoides ass. nova

Sinıf: ARTHROCNEMETEA (Syn:

Salicornetea fruticosae)

Ordo: ARTHROCNEMETALIA (Syn:

Salicornetaliea fruticosae)

Alyans: HALOCNEMENION

STROBILACEI Géhu \& Costa in Géhu,

Costa, Biondi, Peris \& Arnold 1984

Birlik: Arthrocnemo-Halocnemetum

strobilacei Oberd 1957

Birlik: Tamaricetum smyrnensis Seçmen \& Leblebici 1996

Sinıf: CISTO-MICROMETERIETEA

Oberdorfer 1954

Ordo: CISTO-MICROMERIETALIA

Oberdorfer 1954

Birlik: Cisto-Corydothymetum capitatus Yolcu 2005

Birlik: Erico-Pistacietum lentisci ass. nova

Sinıf: QUERCETEA ILICIS Br.-Bl. ex A. de Bolòs Y Vayreda 1950

Ordo: QUERCETALIA ILICIS Br.-B1. 1947

Birlik: Asphodelo-Sarcopoterietum spinosi Durmuşkahya 2005

Birlik: Lino-Pinetum brutiae Durmuşkahya 2005

\section{Kıyı kumul vejetasyonu}

Birlik: Medicio marinae - Cakilietum maritimae ass. nova Holotip no: 82

Yayılış: Birlik özellikle Selçuk-Pamucak deresi kenarı kumsal alanlarda gözlenmiş ve tanımlanmıştır. Birliğe ait karakteristik türler: Medicago marina L., Cakile maritima Scop. Ammophillion austrialis alyansina ait karakteristik türler: Ammophila arenaria, Elymus farctus, Otanthus maritimus, Eryngium maritimum. Yapilan arazi çalışmaları sonucunda Medicago marina ve Cakile maritima'nın denize en yakın psammofitler olduğu gözlendi. Sykora vd. (2003), Yunanistan kıyıları ve Ege Denizine komşu diğer ülkelerin kıyı şeridi ve kumsallarda yaptıkları çalışmada kıyı şeridinde Salsola kali-Cakiletum maritimae bitki birliğini belirlemiş ve bu birliği Cakiletum maritimae sinıfına dahil etmişlerdir. Belirlediğimiz birlik, kıyı çizgisine en yakın birliklerden biri olmasına karşın floristik bileşiminde yer alan türlerin çok yıllık ve rizomlu olmaları nedeniyle bu son üniteye dahil edilmesi uygun görülmemiştir. Toprak analiz sonuçlarına göre birlik, tuzsuz, kireçsiz ve alkali topraklar üzerinde bulunmaktadır.

\section{Birlik: Euphorbio paraliae- Ammophiletum arundinaceae Uslu 1985}

Yayılıș: Dikili, sahil kenarı kumul; Çeșme, Altınkum plajı kumul; Selçuk-Pamucak sahili, kumul. Karakteristik türler: Ammophila arenaria subsp. arundinacea, Euphorbia paralias L., Limonium bellidifolium (Gouan) Dumort., Silene colorata Poiret, Arundo donax L. Ammophillion austrialis alyansının karakteristik türleri: Eryngium maritimum, Pancratium maritimum, Sporobolus virginicus, Lagurus ovatus, Otanthus maritimus, Centaurea spinosa.

Birlik ilk defa Uslu (1985) tarafindan Küçük Menderes ile Büyük Menderes nehirleri arasında kalan bölgede tespit edilmiştir. Ayrıca birlik Görk ve ark.(2001) tarafından Çeşme Yarımadası'nda da incelenmiştir. Uslu (1985)'nun belirlediği birlikte karakteristik ve ayırt edici türler Ammophila arenaria subsp. aundinaceae ve Maresia nana'dır. Görk ve ark. (2001) bu birliği Euphorbio paraliae-Ammophiletum arundinaceae birliği olarak isimlendirmiş ve Ammophiletea sinifi Ammophiletalia ordosu ve Ammophilion alyansına bağlanmıştır. Alanın toprağı tuzsuz, $\mathrm{P}, \mathrm{K}, \mathrm{Fe}, \mathrm{Cu}, \mathrm{Zn}$ ve $\mathrm{Mn}$ 
gibi bitkiler için faydalı elementler bakımından fakirdir. Bunun plajdaki kumulların tahribata bağlı taşınmasından kaynaklandığı düşünül-mektedir.

\section{Birlik: Anthemo tomentosae- Centauretum spinosae ass. nova holotip no:100}

Yayılış: Çandarlı, Bakırçay deltası, tuzcul; Dikili, sahil kenarı, kumul; Karaburun Yarımadası, sahil, kumul; İzmir-Özdere yakınları, sahil, kumul; İzmir, Ürkmez sahili, kumul; Edremit, Akçay, Zeytinli sahili, kumul; Balıkesir, Ayvalık, Keremköy civarı, kumul. Karakteristik türler: Centaurea spinosa L. var. spinosa, Cichorium inthybus L., Anthemis tomentosa L. subsp. tomentosa. Ammophillion austrialis alyansinın karakteristik türleri: Medicago marina, Elymus farctus, Sporobolus virginicus, Pancratium maritimum, Lagurus ovatus, Sporobolus nigricans, Otanthus maritimus, Euphorbia paralias. Birlik kumul alanlarda tespit edilmiştir. Centaurea spinosa var. spinosa deniz kenarında Ammophila arenaria'nın arkasında görülür. $\mathrm{Bu}$ alanda kum sabitlenmiş, flora ve fauna bu duruma bağlı olarak daha zengin hale gelmiştir. Seçmen (1977), Gökçeada ve Bozcaada'da Centaurea spinosa var. spinosa birliğini belirlemiştir. $\mathrm{Bu}$ birlikte Sarcopoterium spinosum, Coridothymus capitatus ve Anthyllia hermanniae gibi türler de bulunmaktadır. Çalışmamızda birliğin belirlendiği örnek alanlarda bu bitkilere rastlanmamıştır.

Tuzcul ve sucul vejetasyon

\section{Birlik: Arthrocnemo-Halocnemetum strobilacei Oberd 1957}

Yayılış: Küçük Menderes ve Bakırçay Deltaları ve Eski Gediz yatağı. Karakteristik türler: Arthrocnemum fruticosum, Halocnemum strabiolaceum. Salicornietea fruticosae (syn: Arthrocnemetea fruticosi) ve Salicornietalia fruticosae karakteristikleri: Halimione portulacoides, Salicornia europea, Aeluropus littoralis, Tamarix smyrnensis, Suaeda altissima, Scirpoides holoschoenus.
Birlik, Durmuşkahya (2005) tarafından Gediz Deltası ve Homa Dalyanı çevresinde tespit edilerek Arthrocnemetea sinifinin Arthrocnemetalia fruticosi ordosuna bağlanmış, alyans düzeyinde bir ayrıma gidilmemiştir.

\section{Birlik: Tamaricetum smyrnensis Seçmen \& Leblebici 1996}

Yayılış: Bakırçay, Küçük Menderes Deltası, kumul; Büyük Menderes Deltasının, tuzlu toprakları, Karaburun-Gülbahçe deresi ve Eski Gediz yatağı. Karakteristik türler: Tamarix smyrnensis, Salsola soda. Salicornietea fruticosae (syn: Arthrocnemetea fruticosi) ve Salicornietalia fruticosae karakteristikleri: Halimione portulacoides, Salicornia europea, Juncus inflexus, Limonium virgatum, Hordeum marinum var. marinum, Arthrocnemum fruticosum, Juncus acutus. Uslu (1985) Büyük Menderes ve Küçük Menderes Havzaları'nda yaptığ1 çalışmalarda Tamarix smyrnensis türünü tespit etmiş, ancak birlik olarak irdelememiştir. Durmuşkahya (2000) Dilek Yarımadası ve Büyük Menderes Deltası Milli Parkında yaptığı çalışmada Dil Gölü çevresinde yoğun olarak bulunan Tamarix smyrnensis topluluğundan bahsetmiş, ancak fitososyolojik olarak ele almamıştır. Durmuşkahya (2005) Gediz Deltasının güney kısımlarında bu birliği tespit etmiş ve birliği Artrhocnemetea sinifinın Arthrocnemetalia ordosuna bağlamıştır.

Birlik: Salicornio europeae-Juncetum acutus ass. nova, holotip no: 135

Yayılış: Büyük Menderes Deltası, alkali topraklar; Karaburun Yarımadası, Karaburun yolu Sazadin deresinin kıyı; Gökova körfezi azmaklar arası; Muğla, Milas Metruk tuzlası, bataklık alanlar; Selçuk, Küçük Menderes Deltası kıyılar; İzmir-Alaçatı Yumru limanı, bataklık alanlar; Alaçatı-Mersin koyu, kıyı tuzcul. Karakteristik türler: Juncus acutus, Salicornia europea. Salicornietea fruticosae (syn: Arthrocnemetea fruticosi) sinifi ve Salicornietalia fruticosae ordosu karakteristikleri: Halimione portulacoides, 
Inula crithmoides, Plantago crassifolia, Halocnemum strabilaceum, Suaeda prostrata, Schoenus nigricans, Salsola kali, Juncus maritimus, Salsola soda, Arthrocnemum fruticosum, Salsola ruthenica. Birlik içerisinde Ammophilion australis alyansına ait azımsanmayacak kadar karakteristik tür bulunmaktadır. Zira birlik kıyısal habitatlarda belirlendiğinden dolayı bu alanlarda k1yı kumullarında bulunan Ammophilion australis alyansına ait karakteristik türlerin bulunması da normaldir. Pandza ve ark. (2007)'nin Adriyatik kıyılarında yaptıkları çalışmada Juncetum maritimo-acuti birliğini belirlemişler ve birliği Juncetea maritimi sinıfi ve Juncion (etalia) maritimi ordo ve alyansına bağlamışlardır.

Birlik: Parapholio incurvaeAeluropetum littoralis ass. nova holotip no: 67

Yayılış: Büyük Menderes deltası; Akbük sahili, kumul; Gökova Körfezi, Azmak deresi, tuzlu alanlar; Selçuk-Pamucak sahili, Pamucak deresi yakını; Ayvalık, Alibey Adası, kıyı tuzcul; Ayvalık, Bedavut sahili kıy1. Karakteristik türler: Aeluropus littoralis, Parapholis incurva. Salicornietea fruticosae sinıfi ve Salicornietalia fruticosae ordosunun karakteristikleri: Juncus acutus, Plantago maritima, Salsola kali, Inula crithmoides, Limonium sinuatum, Salicornia europea, Salsola soda, Halimione portulacoides. Birlik içerisinde tuzcul habitatlarda yayılış gösteren Salicornietae fruticosae ve k1y1 kumullarda bulunan Cakiletea maritimae ve Ammophiletea sınıfina ait karakteristik türler az yoğunlukta bulunmaktadır. Bu yüzden birliğin kumul ve tuzcul vejetasyonunun tahribiyle ortaya çıktığı düşünülebilir.

\section{Birlik: Salicornio europeae- Halimionetum portulacoides ass. nova, holotip no: 78}

Yayılış: Gökova körfezi kuzey kıyıları; Milas Kıyıkışlacık köyü kıyıları; Balıkesir Akçay kıyıları; Dikili, Altınova sahili kumsal; Dilek Milli Parkı Nero koyu civarı, kıyı tuzcul. Karakteristik türler: Halimione portulacoides, Salicornia europea. Salicornietea fruticosae sinıfinın karakteristikleri: Arthrocnemum fruticosum, Salsola soda, Salsola kali, Limonium virgatum, Halocnemum strabilaceum, Inula crithmoides, Suaeda prostrata subsp. prostrata. Birlik, Salicornietea fruticosae sınıfının Salicornietalia fruticosae ordosuna ait çok sayıda karakteristik içerdiğinden ve birliğin bulunduğu habitatların daha önce belirtildiği üzere söz konusu sınıf ve ordonun habitatları ile uygun olmasindan dolayı bu sinif ve ordoya dahil edilmesi uygun görülmüştür. Birlikte az sayıda Saginetalia maritimae sinıfi, Limonietalia ordosu karakteristikleri bulunmaktadır.

\section{Frigana vejetasyonu}

Birlik: Asphodelo-Sarcopoterietum spinosi Durmuşkahya 2005

Yayılış: Foça kıyı, malilik alan; Foça frigana; Foça-Yeni Foça arası yol kenarı; Karaburun Yarımadas1, frigana; Bodrum Karg1 plaj1 arkası; Bodrum-Ortakent yahşi, tepeler, frigana; Aydın Dilek Milli Park1, Bademlik mevkii, maki açıklığı; İzmir, Alaçatı, kıyı kenar, frigana. Karakteristik türler: Sarcopoterium spinosum, Asphodelus aestivus. Quercetalia (etea) ilicis' in karakteristik türleri: Calicotome villosa, Lavandula stoechas subsp. Stoechas, Quercus cocciferae, Asparagus acutifolius, Pistacia terebinthus, Erica manipuliflora, Ruscus aculeatus, Pinus brutia, Anagyris foetida, Cynosurus echinatus, Juniperus oxycedrus subsp. macrocarpa. Birlik, araştırma alanında kalker anakaya üzerinde kireçsiz kahverengi topraklarda tespit edilmiştir. Birlik, Durmuşkahya (2005) tarafindan AsphodeloSarcopoterietum spinosi birliği olarak isimlendirilmiş ve bu birlik, Quercetalia (etea) ilicis ordo ve sınıfına dahil edilmiştir. Ancak alyans düzeyinde bir ayrıma gidilmemiştir.

\section{Birlik: Cisto - Coridothymetum} capitatus Yolcu 2005

Yayılıș: Çeșme Altınkum plajı, frigana; Karaburun Yarımadası, kıyı, frigana; Ayvalık, Pelitköy, makilik alanlar; Ayvalık, Tilki koyu kıyı kenar, frigana; Ayvalık, Keremköy, kıyı 
kenar; İzmir, Urla, Zeytineli koyu, makilik alan. Karakteristik türler: Coridothymus capitatus, Cistus creticus. CistoMicromeritalia (etea)'nın karakteristik türleri: Sarcopoterium spinosum, Osyris alba, Genista acanthoclada, Thymelea tartonraira, Cistus parviflorus, Cistus salviifolius, Teucrium polium, Anthyllis hermanniae, Lavandula stoechas, Juniperus phoenicia, Erica manipuliflora, Chamaecystus hirsutus, Ephedra campylopoda. Birlik ilk defa Yolcu (2005) tarafından Kızıldağ'da (Hatay) denize bakan yamaçlarda kumtaşı üzerinde tespit edilmiş ve Cisto-Micromerietea sınıfına dahil edilmiştir. Ayrıca Bekat ve Seçmen (1988) Foça, Aliağa ve Çandarlı arasındaki bölgede frigana vejetasyonunda Cistus salviifolius bitki grubunu tespit etmişlerdir. $\mathrm{Bu}$ bitki grupları içerisinde Cistus creticus'un bulunuş değeri fazladır.

\section{Maki vejetasyonu}

Birlik: Erico-Pistacietum lentisci ass. nova, holotip no: 57

Yayılıș: İzmir, Çeşme-Dalyan, sahil, frigana; İzmir, Karaburun Yarımadası, deniz kenarı alanlar; Ayvalık, Bedavut sahili, maki. Karakteristik türler: Pistacia lentiscus, Erica manipuliflora, Erica arborea, Romulea bulbocodium, Romulea linaresii. CistoMicromerietalia (ea) sinıfinın karakteristikleri: Sarcopoterium spinosum Cistus salviifolius, Asphodelus aestivus, Lavandula stoechas, Calicotome villosa, Thymelea tartonraira, Cistus parviflorus, Daphne gnidioides, Corydothymus capitatus, Origanum onites, Spartium junceum, Teucrium polium. Ege ve Akdeniz sahillerinde makilik alanlarda yayılış gösteren ve kültürü yapılan bir türdür. Sintaksonomik olarak birlikte çok sayıda CistoMicromerietalia (ea) karakteristikleri bulunduğundan birlik Cisto-Micromerietalia (ea) ordo ve sınıfına dahil edilmiştir.

\section{Orman Vejetasyonu \\ Birlik: Lino - Pinetum brutiae Durmuşkahya 2005}

Yayılış: Selçuk, Küçük Menderes nehri karşıs1 kayalık alan ve Pinus brutia ormanı; Aydın, Kuşadası, ormanlık alan; Akbük sahil kıy1; Muğla-Akyaka İncekum plajı arkası; Aydın, Dilek Milli Parkı, Dipburun yolu, kıyı yol kenarı. Karakteristik türler: Pinus brutia, Linum corymbulosum. Quercetalia ilicis ordo ve sinıfinın karakteristikleri: Quercus cocciferae, Phillyrea latifolia, Asparagus acutifolius, Juncus acutus, Asphodelus aestivus, Pistacia lentiscus. Gemici (1981) Yamanlar Dağı'nda yaptığı çalışmada bu bölgedeki Pinus brutia topluluklarını Quercetalia (ea) ilicis'e dahil etmiştir. Özel (1998) Kazdağları'nda yaptığı çalışmada, bu birliği kireçsiz anakaya üzerinde gelişen regosol topraklar üzerinde tespit etmiş ve Quercetalia (ea) ilicis ordo ve sinifi ile Quercion ilicis alyansına dahil etmiştir. Durmuşkahya 2005 tarafından ilk kez tanımlanan birlik, Yamanlar Dağı'nın kuzey sırtlarında, Manisa Dağı'nın eteklerinde ve Turgutlu ile Salihli 'nin kuzey yamaçlarında örneklenmiștir. Fitososyolojik olarak ta Quercetalia (ea) ilicis ordo ve sinıfına dahil edilmiş ancak alyans düzeyinde bir ayrıma gidilmemiştir.

\section{Sonuç}

Antropojenik gelişmeler ve faaliyetler Kıyı Ege'de biyoçeşitlilik üzerinde baskı oluşturmaktadır. Alanda da ulusal mevzuat ve uluslararası sözleşmeler gereği koruma altında bulunan flora türü bulunmamaktadır. Ancak bu mevcut flora türlerinin önemsiz olduğu anlamına gelmemektedir. Diğer yandan CITES sözleşmesi uyarınca; Alanda bulunan Anemone coronaria, Cyclamen hederifolium, Sternbergia schubertii Schenk, Sternbergia lutea (L.) Ker. Gawler ex Sprengel, Orchis coriophora L., Orchis morio L. subsp. picta (Loisel.) K. Richter, Orchis papilionaceae L. var. papilionaceae, türleri ile Amaryllidaceae, Liliaceae, Orchidaceae, Iridacea ailelerine ait türler CITES kapsamında koruma altındadır (CITES, 2017). Bütün koylar, özellikle su dengesinin sağlanmasında büyük önem 
taşırlar. Gediz deltasının güneydoğusunun doldurularak yapılaşmaya açılması alanın ve çevresinin ekolojik yapısını bozmuştur. Hidrolojik döngülerin kesilmesi alanda su baskınlarına ve çökmelere neden olmaktadır. Çalışma alanımızda tarımsal etkinliğin maalesef çok yaygın olması ve sulu tarım yapılması nedeniyle bazen akarsu yataklarına bile kuyular açılarak kontrolsüz sulama yapılmaktadır. Sel sulama denilen bu yöntem, iklimin sicak olması nedeniyle, evaporasyonla toprağın alt katmanlarındaki mineral tuzları toprağın bitkiler tarafından kullanılan üst kesimlerine çkarmakta ve bu durum çoraklaşma dediğimiz olaya yol açmaktadır. Özellikle Batı ve Güney Anadolu'daki delta ovalarındaki en ciddi sorun çoraklaşma olgusudur. Bu nedenle yapılacak çalışmalar tüm havzayı kapsayacak ölçüde olmalı ve havza boyunca arazi kullanımına yön vermelidir.

Kıyı Ege'de ekolojik yönetimle ilgili 3 önemli unsur önerilebilir:

- Mevcut halin korunmas1,

- Rehabilitasyon çalışmaları

- Restorasyon

çalışmalarının yap1lmas1.

Çalışma alanında paraklimaks konuma gelmiş vejetasyonun restorasyonu oldukça zor görülmekte, bu nedenle bu alanlarda rehabilitasyon çalışmaları uygulanmalı ve arazi kullanımı bu yönde şekillendirilmedir. Buna karş1lık henüz yapılaşma ve kirletici unsurlar tarafından ciddi biçimde bozulmamış kumul ve delta ovalarında restorasyon çalışmaları gerçekleştirmek için herhangi bir doğal engel bulunmamaktadır. $\mathrm{Bu}$ alanlara ilişkin mümkün olduğunca küçük ölçekli arazi kullanım planları yapılmalı, bu planlar ekolojik tampon bölgenin dişında tutulmalıdır. Benzer ssekilde havza bazında gerçekleştirilecek su yönetim planları ile deltalara gelmesi gereken asgari suyun bu alanlara verilmesi büyük önem taşımaktadır. Çalıșma alanımızdaki akarsuların kontrolsüz kullanımı dikkate alındığında bu durumun gerçekleşmesi zor değildir. Tatlı suyun gelmesi sonucu deniz suyunun çekileceği ve su basar otlar, çayır, saz ve kamışların tekrar yeşereceği ve çokta uzun olmayan zaman içerisinde ekolojik dengenin sağlanacağ açıktır. Bu dengenin sağlanması yani gerekli restorasyon çalışmalarının yapılması sonucu söz konusu alanlar, kaybettikleri biyolojik zenginliklerine tekrar kavuşabileceklerdir. Zira dünyanın birçok bölgesinde gerçekleștirilen benzer çalıșmalar, restorasyona bağlı olarak doğada geri kazanım ilkesinin son derece sağlıklı çalıştı̆̆ını ortaya koymuştur. Dünyanın pek çok yerinde kıyı alanlarının yönetimi, kumul erozyonu ile mücadele, kumul stabilizasyonu ve ağaçlandırma, turizm, kentleşme ve rekreasyonda bilgilendirme ve eğitim gibi birçok işlevi yerine getirmektedir (Meulen ve Salman, 1996). Güneydoğu Florida'da kıyı sulak alanların restorasyonu ile ilgili bir çalışmada kamuya alanlarda yerel yönetimlerle birlikte yapılacak restorasyon çalışmalarının önemine dikkat çekmektedir. $\mathrm{Bu}$ kapsamda öncelikle sulak alanlardaki egzotik bitkilerin ve kanal gibi sonradan yapılan oluşumların kaldırılıması, önceki vejetasyonunun tekrar canlandirılması ve vejetasyona uygun faunanın gelişiminin sağlanması şekilinde yönetim planlaması çalışmaları yapılmıştır (Milano, 1999).

\section{Teșekkür}

Bu çalıșma doktora tezinin bir bölümünü oluşturmaktadır ve Ege Üniversitesi Araştırma Fonu tarafından desteklenmiştir. (Proje no: 2007Fen22). Finansal desteklerinden dolayı teşekkürü borç bilirim. Ayrıca bu çalışmayı 23.11.2015 tarihinde vefat eden danışmanım Prof. Dr. Yusuf GEMİCI'nin anısına armağan ediyorum.

\section{Kaynaklar}

Bekat L, 1980. Karaburun-Akdağ çevresinin flora ve vejetasyonu. Ege Üniversitesi Fen Bilimleri Enstitüsü, Yüksek Lisans tezi, 34 s. İzmir. 
Bekat L, Seçmen Ö, 1988. Vegatation In der umgebung von Foça, Aliağa und Çandarlı, Journal of Faculty of Science Ege University Series B, 10 (2).

Braun-Blanquet J., 1932. Plant sociology, Mc Graw-Hill Book Co. Inc., First Edition, New York and London.

CITES, 2017. http://checklist.cites.org/ Son Erişim Tarihi 27/01/2017.

Davis P.H., 1965-1985. Flora of Turkey and the East Aegean Islands. Vol. 1-9, Edinburgh.

Davis P.H., Mill R.R., Tan K., 1988. Flora of Turkey and the East Aegean Islands. Vol.10 supplement, Edinburgh. 590 p.

Durmuşkahya C., 2000. Dilek Yarımadası Büyük Menderes Deltası milli parkı biyoçeşitliliği üzerine incelemeler. Ege Üniversitesi Fen Bilimleri Enstitüsü, Yüksek Lisans Tezi, 121s.

Durmuşkahya C., 2005. Aşağı Gediz Havzası Vejetasyon Ekolojisi. Celal Bayar Üniversitesi Fen Bilimleri Enstitüsü, Doktora Tezi, 179s.

Eken G., Bozdoğan M., İsfendiyaroğlu S., Kılıç D.T., Lise Y., 2006. Türkiye'nin Önemli Doğa Alanları. Doğa Derneği, Ankara, 79 s.

Gemici Y., 1981. Yamanlar Dağ1 (İzmir) ve çevresinin flora ve vejetasyonu, Ege Üniversitesi Fen Bilimleri Enstitüsü, Yüksek Lisans Tezi. 81s.

Görk G., Oluk S., Şenol S.G., Gemici Y., 2001. The Vegetation of Çeşme (İzmir) Peninsula II. Journal of Faculty of Science Ege University, 24(1):121-132.

Güner A., Özhatay N., Ekim T., Başer K.H.C., 2000. Flora of Turkey and East Aegean Islands. Vol.11 (suppl.2) Edinburgh, 619 p.

Meulen F., Salman, A.H.P.M, 1996. Management of Mediterranean coastal dunes, Ocean \& Coastal Management, Vol. 30, Nos 2-3, pp. 177-195.

Milano G.R., 1999. Restoration of coastal wetlands in southeastern Florida. Wetland Journal 11(2): 15-24.

Oluk S., Görk G., Şenol S.G., Gemici Y., 2001. The Vegetation of Çeşme (İzmir) Peninsula I. Journal of Faculty of Science Ege University, 24(1): 107-119.

Özel N., 1998. Kaz Dağları orman vejetasyonu üzerine fitososyolojik ve fitoekolojik araştırmalar. Ege Üniversitesi Fen Fakültesi, Doktora Tezi, $187 \mathrm{~s}$.

Pandza M., Franjic J., Skvorc Z., 2007. The salt marsh vegetation on the East Adriatic coast. Biologia Bratislava, 62(1): 24-31.
Pirhan A.F., Gemici Y., 2015. Didim, Milas, Ören ve Bodrum (Türkiye) florası. Bağbahçe Bilim Dergisi, 2(2): 68-89.

Quézel P., Barbero M., Akman Y., 1992. Typification de syntaxa décrits en Région mediterranéenne orientale. Ecologia Mediterranea, 18: 81-87.

Seçmen Ö., 1977. Nif Dağı'nın vejetasyonu ve florası üzerine bir inceleme. Ege Üniversitesi Fen Fakültesi, Doçentlik Tezi.

Seçmen Ö., Leblebici E., 1996. Marmara bölgesi sulak alanlarının bitki örtüsü. Journal of Botany, 20: 171-187.

Sykora K.V., Babalonas D., Papastergiadou E.S., 2003. Strandline and sand-dune vegetation of coasts of Greece and some Other Aegean countries, Phytocoenologia, 33(2-3): 409-446.

Uslu T., 1985. Aydın'ın batısında Küçük ve Büyük Menderes nehirleri arasında kalan bölge vejetasyonunun bitki ekolojisi ve sosyolojisi yönünden araştırılması. Gazi Üniversitesi FenEdebiyat Fakültesi Yayınları, No:8, Ankara.174s.

Yolcu H., 2005. Kızıldağ (Hatay) Vejetasyonunun araştırılması, Çukurova Üniversitesi. Fen Bilimleri Enstitüsü, Doktora tezi, $87 \mathrm{~s}$.

Weber H.E., Moravec J., Théurillat, J.P., 2001. Code of phytosociological nomenclature. Journal of Vegetation Science, 11: 739-768. 